\title{
Bacterial Contamination of Blood and Blood Products at Mbarara Regional Blood Bank in Rural South Western Uganda
}

\author{
G. B. Matte Aloysius ${ }^{1,2 *}$, Bazira Joel ${ }^{1}$, Richard Apecu' ${ }^{2}$, Boum Yap II $^{3}$, Frederick Byarugaba ${ }^{1}$ \\ ${ }^{1}$ Department of Microbiology, Faculty of Medicine, Mbarara University of Science and Technology (MUST), Mbarara, Uganda; \\ ${ }^{2}$ Department of Medical Laboratory Science, Faculty of Medicine, Mbarara University of Science and Technology, Mbarara, Uganda. \\ ${ }^{3}$ Epicentre Mbarara Research Base, Mbarara, Uganda; \\ Email: *mattealoysius@yahoo.com
}

Received July $9^{\text {th }}$, 2013; revised August $7^{\text {th }}, 2013$; accepted August $16^{\text {th }}, 2013$

Copyright (c) 2013 G. B. Matte Aloysius et al. This is an open access article distributed under the Creative Commons Attribution License, which permits unrestricted use, distribution, and reproduction in any medium, provided the original work is properly cited.

\begin{abstract}
Background: Screening blood donors has practically eliminated viral and bacterial pathogens in blood used for transfusion. However, transfusion-associated bacterial sepsis remains an important health-care concern and the commonest cause of transfusion-related fatality in resource limited settings. Data on bacterial contamination of blood are scarce while the demand of blood transfusion is continuously growing. Therefore we conducted a study to determine the prevalence and type of bacterial contamination in donor blood and blood products, at the Mbarara Regional Blood Bank. Methodology: A total of 510 units of screened blood and blood products consisting of refrigerated whole blood and packed cells were randomly sampled following aseptic procedures from Mbarara Regional Blood Bank. Two samples from each unit were collected in universal containers containing Brain Heart Infusion Broth and incubated at $37^{\circ} \mathrm{C}$ for up to 7 days. Subcultures were carried out on Blood agar, Chocolate agar and MacConkey agar. Isolates were identified by standard microbiologic techniques and drug susceptibility testing was performed by Kirby Bauer disc diffusion method. Results: Of the 510 samples collected between June and October 2012, 18 (3.5\%) samples showed growth. The contaminants were Staphylococcus aureus 17/18 (94.4\%) and Streptococcus viridans 1/18 (5.6\%). Isolates were sensitive to erythomycin, ampicillin, chloramphenicol and ciprofloxacin and resistant to penicillin and cloxacillin. Conclusion: Blood and blood products from Mbarara Regional Blood have unacceptable levels of bacterial contamination that can affect patient safety especially in an area with high malaria endemicity. Therefore it is critical to improve hygiene precautions in order to minimize bacterial contamination and ensure patient safety.
\end{abstract}

Keywords: Bacterial Contamination; Blood/Blood Products; Staphylococci

\section{Introduction}

Blood transfusion is a medical intervention intended to provide safe blood or blood components in a cost effective way to patients who require blood and/or blood products. However, blood and blood components for transfusion can be a source of infection to recipients arising from contamination of these products by a variety of transmissible agents. Since the 1980's when the human immunodeficiency virus (HIV) was recognized, rigorous screening of blood before it is supplied to recipients was instituted and accepted worldwide [1]. Uganda adopted this rigorous screening of blood in order

\footnotetext{
${ }^{*}$ Corresponding author.
}

to provide safe blood to her population. Blood is screened for viruses including the Human Immunodeficiency virus (HIV), Hepatitis B virus (HBV), Hepatitis C (HCV) and for Treponema pallidum, a bacterium. It has been documented that bacteria can cause morbidity and mortality from blood and blood transfusion components $[2,3]$.

In developed countries, transfusion of blood and blood components has a low but known infectious risk for patients and remains a threat $[4,5]$. In the United States, bacterial contamination is said to account for $15.9 \%$ of all transfusion related fatalities, and is considered the second commonest cause of death from blood transfusion after clerical errors $[4,6]$. Recent data indicate that bacterial contamination has declined by about $50 \%$ or more 
with contamination being detected in about one in 5000 apheresis platelet concentrates tested [3,7]. The possibility and problem of bacterial contamination of blood and blood products have received very little attention on the African continent [3]. Few countries in Africa have published records of bacterial contamination of blood/blood products. These include Ghana [2,8], Kenya [9] and, Nigeria [3]. Many African countries do not have documented reports on bacterial contamination of blood and blood products and no record whether these products do pause a risk of causing morbidity and mortality among recipients [3]. To the best of our knowledge, in Uganda, no research has been carried out to determine blood transfusion-associated infections or whether the blood and blood components intended for transfusion may be contaminated with bacteria. Therefore we performed this study to determine the prevalence of bacterial contamination of blood and blood products supplied by the Mbarara Regional Blood Bank, identify the types of contaminating bacteria and determine their antibiotic susceptibility pattern.

\section{Materials and Methods}

This was a descriptive cross-sectional study conducted at the Mbarara Regional blood Bank located in the South Western Region of Uganda. A total of 510 samples of blood were collected from blood donors between June and October 2012 and were selected using non probability convenient sampling. Blood and blood products included in this study were those that had been screened and found negative for Human Immunodeficiency virus, Hepatitis B virus, Hepatitis C virus and Treponema pallidum and had been stored for not more than 35 days.

\subsection{Blood and Blood Product Collection from Blood Bag Units}

Blood bags were conveniently sampled. Refrigerated stored blood in bags was thoroughly mixed, and the tubing was then swabbed with $70 \%$ ethanol pads and a sterile syringe was used to withdraw blood from the blood bag through the line and some of the mixed blood from the main bag was allowed to seep into the line. About five milliliters were withdrawn by use of a $5-\mathrm{ml}$ sterile syringe and $2.5 \mathrm{ml}$ transferred to each of the two Universal bottles containing the Brain Heart Infusion (BHI) broth. The end of each line was then sealed to prevent blood in the line and air from flowing back into the main bag. Two seals were made, one before the punctured site to prevent blood from flowing back to the main blood bag, and the other after the puncture site. The BHI blood culture bottle cover was then sterilized by flaming before and after inoculation.
The two BHI sample suspensions were incubated at $37^{\circ} \mathrm{C}$ and observed daily for any possible signs of bacterial growth (pellicle formation, hemolysis, or turbidity) for 7 days. Samples found with bacterial growth were sub cultured using a sterile wire loop-full of each sample onto blood agar, Chocolate agar and MacConkey agar plates. Samples were incubated overnight (18 - 24 hours) at $37^{\circ} \mathrm{C}$. A blind sub culture was performed for samples which showed no growth on the seventh day. Any bacterial growth was identified using colonial morphology, Gram stain reaction, and standard biochemical reactions.

\subsection{Antibiotic Susceptibility Testing}

Antibiotic susceptibility testing was performed by the Kirby Bauer disc diffusion method [10]. The following antibiotic discs were used: ampicillin $(10 \mu \mathrm{g})$, penicillin $(10 \mu \mathrm{g})$, chloramphenicol $(10 \mu \mathrm{g})$, cloxacillin $(5 \mu \mathrm{g})$, ciprofloxacin $(5 \mu \mathrm{g})$, erythromycin $(15 \mu \mathrm{g})$, and interpreted according to the Clinical and Laboratory Standards Institute [11] guidelines.

\subsection{Quality Control}

Aseptic techniques were observed at all times during the collection of the samples. Standard operating procedures were employed throughout the whole investigative process including use of standard Staphylococcus aureus (ATCC 25923) for Gram-positive organisms. Standard materials supplied by accredited manufacturers were used in the study.

\section{Results}

Of the 510 blood and blood products, 18 units had bacterial growth, indicating a 3.5\% prevalence of bacterial contamination of blood/blood products at the Mbarara Regional Blood Bank. However, the level of contamination was higher in packed cell units than in whole blood (see Table 1).

The majority of isolates 17/18 (94.4\%) were Gram positive, coagulase positive Staphylococcus aureus, while Gram positive Streptococcus viridans contributed 1/18 (5.6\%) of the contamination (see Table 2).

The $S$. aureus isolates showed a high sensitivity to ampicillin, chloramphenicol, erythromycin and cipro-

Table 1. Level of contamination according to blood component.

\begin{tabular}{cccc}
\hline Type of blood component & $\begin{array}{c}\text { Growth } \\
(\mathrm{n} \%)\end{array}$ & $\begin{array}{c}\text { No growth } \\
(\mathrm{n} \%)\end{array}$ & $\begin{array}{c}\text { Total } \\
(\mathrm{n} \%)\end{array}$ \\
\hline Whole blood & $8(2.5)$ & $309(97.5)$ & $317(100)$ \\
Packed cells & $10(5.2)$ & $183(94.8)$ & $193(100)$ \\
Total & $\mathbf{1 8 ( 3 . 5 )}$ & $492(96.5)$ & $510(100)$ \\
\hline
\end{tabular}


Table 2. Level of contamination according to type of bacteria.

\begin{tabular}{cccc}
\hline Bacteria type & \multicolumn{3}{c}{ Number of blood units contaminated } \\
\hline Bacteria type & Whole blood & Packed cells & Total \\
S. aureus & 8 & 9 & $17(94.4 \%)$ \\
S. viridans & 0 & 1 & $1(5.6 \%)$ \\
Total & 8 & 10 & $18(100 \%)$ \\
\hline
\end{tabular}

floxacin. A high resistance of these strains to peniciliin and cloxacillin was observed (see Figure 1). The S. viridans isolated in one unit of packed cells showed resistance to penicillin and cloxacillin and was sensitive to chloramphenicol, ampicillin, ciprofloxacin, and erythromycin (data not shown).

Highest resistance to Penicilin and cloxacillin and lowest resistance to Erythromycin was observed.

\section{Discussion}

The prevalence of bacterial contamination of blood/blood products of $3.5 \%$ found in this study is lower compared to other studies carried out in Africa-7\% in Kenya, [9], $8.8 \%$ in Nigeria, [3] and between 9 to $17.5 \%$ in Ghana, $[2,8]$. This could be explained by the difference in the settings across the countries and the time since the implementation of rigorous regulations on blood products.

The prevalence of blood contamination in this study is however higher than that reported in developed countries. In the United States, a prevalence of $0.2 \%$ was reported [12], while $0.15 \%$ was reported in the UK [13], and $0.1 \%$ was reported in France [14]. The explanation for lower prevalence in developed countries is attributed to more rigorous screening procedures practiced in these countries.

Nonetheless it should be noted that despite the lower prevalence in developed countries, severe annual morbidity and mortality due to bacterial contamination of blood is considered a cause of significant annual morbidity and mortality [4]. No follow up studies have been carried out in patients transfused with contaminated blood to determine the level of morbidity and mortality in Uganda. Moreover, these data could explain the fever observed usually 5 days after blood transfusion of children treated for severe episodes of malaria in our hospital (Unpublished data).

The organisms isolated in this study were Staphylococcus aureus and Streptococcus viridans. In Ghana, the isolates reported by a study conducted by Adjei were Gram-positive bacteria (S. aureus, Coagulase-negative Staphylococci (CNS), and Bacillus species) and Gram-negative bacteria ( $Y$. enterocolitica, Citrobacter freundii, E. coli, P. aeroginosa, and Klebsiella pneumoniae) [8]. Opoku-Okrah also in Ghana reported only

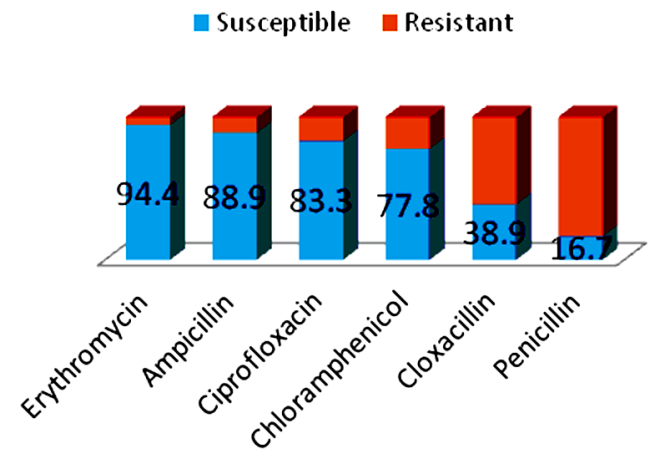

Figure 1. Sensitivity patterns of $S$. aureus to various antibiotics $(\mathbf{n}=17)$.

Gram-positive bacteria which included coagulase negative Staphylococci, Staphylococcus aureus, Corynebacteria. The Gram-negative bacteria identified included $E$. coli, bacteroides and Klebsiella pneumonia [2]. A similar study conducted in Nigeria reported Gram-positive bacteria (S. aureus, CNS, Bacillus spp, Listeria spp) to have been isolated [3]. In Kenya, the isolates included Gram-negative organisms (Acinetobacter spp., Aeromonas spp., Brevundemonas vescularis, Burkholderia cepacia, Enterobacter sekazaki, Klebsialla pneumonia, Ochrobacterum anthropi, Oligella urethralis, Pseudomonas spp., Rhizobium radiobacter, Shewanella putrefaciens) and Gram-positive bacteria (Bacillus spp., Micrococcus spp.,and Staphylococcus epidermidis) [9]. In the BACON, SHOT, and BACTHEM studies carried out in the United States, UK, and France respectively, Brecher and Hay, reported the following Gram-positive bacteria isolated from red cells implicated in transfusion-associated infections (CNS, Streptococcus spp., Staphyloccocus aureus, Enterococcus feacalis, Bacillus cereus, Propionibacterium acnes,) and Gram-negative bacteria (Serretia liquifaciens, Serratia marcescens, Yersinia enterocolitica, Enterobacter spp., Acinetobacter spp., Pseudomonas spp., E. coli, Klebsiella pneumonia, and Proteus miribalis) [15]. The Staphyloccocus aureus and Streptoccocus viridans isolated in this study are part of the skin normal flora and therefore can easily be introduced in the blood if skin disinfection is not performed properly during bleeding process.

All isolated organisms in this study showed varying susceptibility to the tested antibiotics as indicated in Figure 1. The $S$. aureus organisms showed resistance to commonly used antibiotics including penicillin, cloxacillin, chloramphenicol, ampicillin, ciprofloxacin and erythromycin. The $S$. viridans isolated showed resistance to penicillin and cloxacillin and was sensitive to chloramphenicol, ampicillin, ciprofloxacin and erythromycin. The resistance to cloxacillin and penicillin might be due to these organisms ability to produce beta lactamases (penicillase) that destroy the B-lactam ring 
found in these antibiotics, rendering the antibiotics ineffective. In Ghana, it was reported that all Gram-positive isolates were resistant to cefuroxime, penicillin, ampicillin, and cotrimoxazole but sensitive to cefotoxime, tetracycline, erythromycin, and gentamycin [2,8]. Similarly, all the Gram-negative organisms isolated were resistant to cefotoxime (except $Y$. enterocolitica), tetracycline, ampicillin, cefuroxime, cotrimoxazole, and chloramphenicol but sensitive to amikacin and gentamycin. A study in Nigeria reported resistance to antibiotics tested (ampicillin, cotrimoxazile, erythromycin, penicillin, tetracycline, rifampicin) except gentamycin, and ceftrioxone that ranged from $50 \%$ to $100 \%$ [3].

One possible explanation for the high resistance of donor blood isolates may be associated with the ease of procuring antibiotics over the counter in Uganda, self medication, and shortfalls in infection control [16]. Another possible cause of high resistance could be due to misuse of antibiotics by cattle farmers, Amanya, (unpublished) reported bacterial resistance to antibiotics on bacteria isolated from milk which included $S$. aureus, Klebsiella pneumonia, S. agalactiae, and E. coli which showed resistance to the commonly used antibiotics including tetracycline, gentamycin and penicillin. This can imply that people consuming milk and milk products may acquire bacterial strains from milk and milk products that are already resistant to the commonly used antibiotics.

\section{Conclusion}

Bacterial contamination of blood was found to be 3.5\%. Staphylococcus aureus was found to be the major contaminant with 17 out of 18 organisms isolated (94.4\%) while Streptococcus viridans contributed 1/18 (5.6\%). The isolates are known to be part of the skin normal flora. The organisms showed increased resistance to penicillin and cloxacillin but susceptible to ampicillin, chloramphenicol, erythromycin and ciprofloxacin.

\section{Recommendation}

While the Mbarara Regional Blood Bank is doing a commendable job in provision of safe blood and blood products emphasis should be put on ensuring proper disinfection of phlebotomy sites.

Policy makers should ensure emphasis of blood safety during phlebotomy by providing quality disinfectants. Routine antibiotic susceptibility testing is recommended in all cases of post-transfusion sepsis.

\section{Acknowledgements}

We appreciate the financial, material and moral support offered to us by Mbarara University of Science and
Technology, Department of Microbiology and; Epicentre Mbarara Research Base. Special thanks to Dr. Atwine Daniel of Epicentre for the support towards the data analysis of our study.

\section{REFERENCES}

[1] American Association of Blood Banks, “Comprehensive Report on Blood Collection and Transfusion in the United States in 2001,” National Blood Data Resource Center, Bethesda, 2003.

[2] C. Opoku-Okrah, P. Feglo, N. Amidu and M. P. Dakorah, "Bacterial Contamination of Donor Blood at Tamale Teaching Hospital, Ghana,” African Health Sciences, Vol. 9, No. 1, 2009, pp. 13-18.

[3] A. R. Bolarinwa, A. A. Oladipo, W. O. Babatunde and B. A. Aramide, "Bacterial Contamination of Blood and Blood Components in a Tertiary Hospital Setting in Nigeria,” International Journal of Infection Control, Vol. 7, No. 1, 2011, pp. 1-6.

[4] C. D. Hillyer, C. D. Josephson, M. A. Blajchman, J. G. Vostal, J. S. Epstein and J. L. Goodman, "Bacterial Contamination of Blood Components: Risks, Strategies, and Regulation: Joint ASH and AABB Educational Session in Transfusion Medicine," Hematology (American Society of Hematology Education Program), Vol. 2003, No. 1, 2003, pp. 575-589. doi:10.1182/asheducation-2003.1.575

[5] C. P. Engelbreit, H. W. Reesink, M. A. Blajchman, et al., "Bacterial Contamination of Blood Components," Vox Sanguinis, Vol. 78, No. 1, 2008, pp. 59-67.

[6] P. A. Hoppe, "Interim Measure for Detection of Bacterially Contaminated Red Cell Components,” Transfusion, Vol. 32, No. 3, 1992, pp. 199-201.

[7] C. T. Fang, L. A. Chambers, J. Kennedy, A. Strupp, M. C. Fucci, J. A. Janas, Y. Tang, C. A. Hapip, T. B. Lawrence and R. Y. Dodd, "Detection of Bacterial Contamination in Apheresis Platelet Products," Transfusion, Vol. 45, No. 12, 2004, pp. 1845-1852.

[8] A. A. Adjei, K. G. Kuma, Y. Tettey, F. P. Ayeh-Kumi, J. Opintan, F. Apeagyei, O. J. Ankrah, K. T. Adiku and E. G. Narter-Olaga, "Bacterial Contamination of Blood and Blood Components in Three Major Blood Transfusion Centers, Accra, Ghana,” Japanese Journal of Infectious Diseases, Vol. 62, No. 4, 2009, pp. 265-269.

[9] O. Hassall, K. Maitland, L. Pole, et al., "Bacterial Contamination of Paediatric Whole Blood Transfusions in a Kenyan Hospital,” Transfusion, Vol. 49, No. 12, 2009, pp. 2594-2598.

[10] A. W. Bauer, W. M. M. Kirby, J. C. Sherris, et al., "Antibiotic Susceptibility Testing by a Standard Single Disc Diffusion Method,” American Journal of Clinical Pathology, Vol. 46, 1966, pp. 493-496. http://202.114.65.51/fzjx/wsw/newindex/wswfzjs/pdf/105 bauer.pdf

[11] CLSI-Performance Standards for Antimicrobial Susceptibility Testing, "Twenty-First Information Supplement," 2011. 
http://antimicrobianos.com.ar/ATB/wp-content/uploads/2 012/.../M100S22E.pdf

[12] M. Kuehnert, V. R. Roth, N. R. Haley, et al., “Transfusion Transmitted Bacterial Infection in the United States, 1998 through 2000,” Transfusion, Vol. 41, No. 12, 2001, pp. 1493-1499.

$$
\text { doi:10.1046/j.1537-2995.2001.41121493.x }
$$

[13] E. M. Love, D. Asher, C. L. J. Atterbury, C. Chapman, H. Cohen, H. Jones, D. R. Norfolk, J. Revill, K. Soldan, A. Todd and L. M. Williamson, "Serious Hazard of Transfusion. SHOT Report for 2000-2001,” 2002. http//www.shot.demon.co.uk

[14] P. L. Perez, R. Salmi, G. Follea, et al., "Determinants of
Transfusion-Associated Bacterial Contamination: Results of the French BACTHEM Case-Control Study,” Transfusion, Vol. 41, No. 7, 2001, pp. 862-871. doi:10.1046/j.1537-2995.2001.41070862.x

[15] M. E. Brecher and S. N. Hay, "Bacterial Contamination of Blood Components,” Clinical Microbiology Reviews, Vol. 18, No. 1, 2005, pp. 195-204. doi:10.1128/CMR.18.1.195-204.2005

[16] I. N. Okeke, R. Laxminarayan, Z. A. Bhutta, A. G. Duse, P. Jenkins, F. O’Brien, A. Pablos-Mendez and K. Klugman, "Antimicrobial Resistance in Developing Countries. Part I: Recent Trends and Current Status,” The Lancet Infectious Diseases, Vol. 5, No. 8, 2005, pp. 481-493. 